\title{
Response Surface Methodology for Optimizing the Degradation of Methyl Orange in Aqueous Solution by a Diaphragm System that Utilizes a Cathode and Anode Coaction Electrochemical Method
}

\author{
Fuchen Ban, Huadong Nan*, Qiu Jin, Meiyue Dai \\ School of Municipal and Environmental Engineering, Shenyang Jianzhu University, Shenyang 110168, China
}

Received: 29 March 2021

Accepted: 15 June 2021

\begin{abstract}
In an electrochemical reactor made by the authors, the degradation of simulated methyl orange wastewater was experimentally studied by using a diaphragm system with an anode and cathode coaction electrochemical method. Response surface methodology was used to optimize the one-factor test results. The optimum condition was that when the voltage was $20.56 \mathrm{~V}$, the distance between the plates was $4.4 \mathrm{~cm}$, and the aeration rate was $2.21 \mathrm{~L} / \mathrm{min}$. The order of influence of each factor was as follows: voltage $>$ distance between electrodes $>$ aeration rate. The two most influential factors were the voltage and aeration rate. Under optimal conditions, the decolorization rate of methyl orange in the cathode chamber reached $90.81 \%$, and in the anode chamber, it was $98.75 \%$. At the same time, the energy expenditure of the diaphragm system during electrolysis is analyzed. UV-visible absorption spectroscopy showed that methyl orange experienced both molecular structure degradation and mineralization during the electrolysis process. The decolorization effect in the anode chamber was better than that in the cathode chamber, but the degree of mineralization of methyl orange in the cathode chamber was better than that in the anode chamber.
\end{abstract}

Keywords: electrochemical method, diaphragm system, energy expenditure, organic wastewater, response surface methodology 


\section{Introduction}

Printing and dyeing wastewater have the following characteristics: complex water quality, large emissions, high chroma and poor biodegradability. If these wastewaters are discharged into natural water without effective treatment, they pose a great threat to the ecological environment and human health [12]. Therefore, in order to minimize the pollution and protect the environment, the pretreatment of dye wastewater discharge is important. At present, the common treatment methods of dye wastewater include physicochemical methods [3], chemical methods [4] and biological methods [5].I $\mathrm{n}$ recent years, the use of electrochemical methods for the treatment of dye wastewater has received extensive attention [6-9]. Electrocatalytic oxidation technology is a new type of advanced oxidation process that directly or indirectly produces strong oxidizing substances through the catalytic oxidation of active electrodes, thereby degrading refractory organics. At present, researchers mostly use electrocatalytic activity (DSA) electrodes as anode materials, mainly through $\mathrm{H}_{2} \mathrm{O}_{2}$ electrolysis, to produce strong oxidizing substances such as $\cdot \mathrm{OH}$ to degrade pollutants. This method has been applied to the treatment of refractory wastewater [10-12]. However, due to the difference in the cathode and anode electrolysis products, the reduction reaction by the cathode cannot directly generate strong oxidizing radicals, so the reduction of organic pollutants by the reduction reaction of the cathode is inefficient. A welldesigned electrochemical reactor can efficiently treat organic pollutants in wastewater by the oxidation of DSA anodes and the oxidation of cathodes. In view of this, the author took methyl orange simulated wastewater as the research object; utilized a diaphragm device in the electrochemical reactor; and selected a titanium plate as the cathode, a titanium-based ruthenium coating as the anode, and polyester 729 as the separator material. Then, the effect of electrochemical catalytic oxidation in the cathode and anode chambers on the degradation of methyl orange was studied. Experiments show that fully utilizing the electrocatalytic oxidation technology of the anode, namely, the reduction of $\mathrm{H}_{2} \mathrm{O}_{2}$ by cathode reduction and the further oxidation of free radicals, which provide more oxidizing ability, can jointly degrade organic pollutants. Thus, the degradation effect of organic pollutants are highly improved, while simultaneously decreasing energy expenditure. The response surface method was used to optimize the influencing factors of methyl orange decolorization in cathode chamber and anode chamber, and more accurate reaction conditions were obtained. This research will lay the foundation for the application of electrochemical technology in wastewater treatment.

\section{Materials and Methods}

\section{Reagents and Instruments}

Methyl orange wastewater was simulated in this study. The wastewater was prepared by adding specific reagents at concentrations of $100 \mathrm{mg} / \mathrm{L}$. Industrial pure methyl orange was purchased from Fuchen Chemical Reagent Factory, Tianjin; Anhydrous sodium sulfate was purchased from China Pharmaceutical Group Chemical Reagent Co. Ltd; Drugs such as concentrated sulfuric acid and sodium hydroxide were all from Tianjin Cobra Chemical Reagent Development Center.

The following instruments were used for testing: a 881-6 thermostatic blast dryer; a JD5000-2 electronic balance; an LZB-3 WB rotor flowmeter; a $8453 \mathrm{UV}-$ Vis spectrophotometer; UV-VIS; a D40-2F electric centrifuge; a YJ65 DC power supply; a ACO-318 rotor flowmeter; a $85 \mathrm{~W}$ UV high-pressure mercury lamp; a PHS-25 acidometer.

The experiment used an electrochemical reactor made by the authors, as shown in Fig. 1.

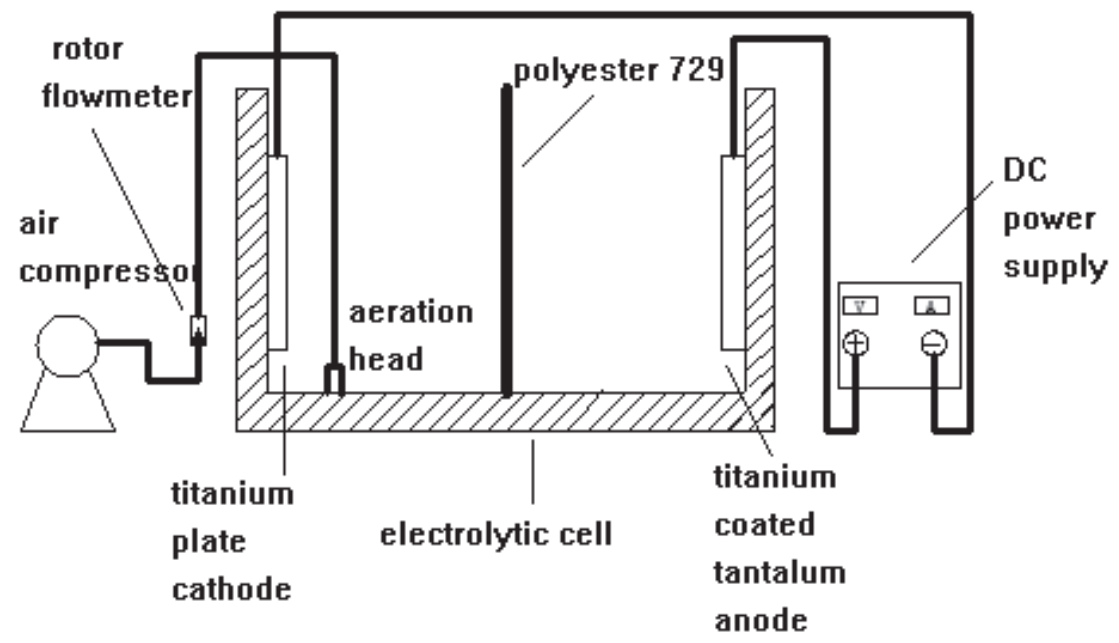

Fig. 1. Schematic diagram of the experimental device. 
The electrolytic cell was made of plexiglass (from Shenyang Donglin plexiglass manufacturer) and had dimensions of $200 \mathrm{~mm} \times 200 \mathrm{~mm} \times 150 \mathrm{~mm}$ and an effective volume of $3.5 \mathrm{~L}$. The diaphragm was fixed in the middle of the cell and measured $150 \mathrm{~mm} \times 150 \mathrm{~mm}$. The anode plate and cathode plate were placed in the groove. The anode material was a titanium-based ruthenium coating. The cathode material was a titanium plate. The plate area was $120 \mathrm{~mm} \times 120 \mathrm{~mm}$, and the distance between the plates could be adjusted.

\section{Pretreatment of test Materials}

\section{Pretreatment of Electrode Plates}

Electrode plates must be soaked in dilute sulfuric acid for $24 \mathrm{~h}$ before using, The surface impurities and organic matter were then washed with deionized water, Then immersed in deionized water for $12 \mathrm{~h}$, placed in $110^{\circ} \mathrm{C}$ drying standby furnace drying reserve.

\section{Pretreatment of Diaphragm Materials}

Flushed the diaphragm material repeatedly with deionized water to remove the surface toner and other impurities, then boiled with deionized water, and finally dried in an electrothermal blast dryer for $120^{\circ} \mathrm{C}$ and set aside.

\section{Test Method}

The treated electrode plates and diaphragm were placed in the reactor, and then adjusted the distance between electrode plates, add $3500 \mathrm{ml}$ of pre-configured methyl orange solution to the electrochemical reactor, added a certain amount of electrolyte, connect air compressor to aeration, regulating air flow through rotor flow meter. Finally, switched on DC Power Supply so that the reaction takes place at a certain voltage. Samples were taken and analyzed every 10 minutes, the absorbance of water samples was measured by UV-Vis Spectrophotometer, Then the decolorization rate of methyl orange was calculated. Tests were performed at room temperature of $20^{\circ} \mathrm{C}$.

\section{Analysis Methods}

\section{$U V-V I S$}

$10,20,30,40,50$ and $60 \mathrm{~min}$ of water samples were selected, then scan on UV-Vis absorption spectra. Wavelength was set between $200 \mathrm{~nm}$ and $700 \mathrm{~nm}$, set to display 3 peaks and 3 valleys.

\section{Determination of Chroma}

A methyl orange solution of $10 \mathrm{mg} / \mathrm{L}$ was selected to determine the absorbance value at different wavelengths, as shown in Fig. 2. The graph shows

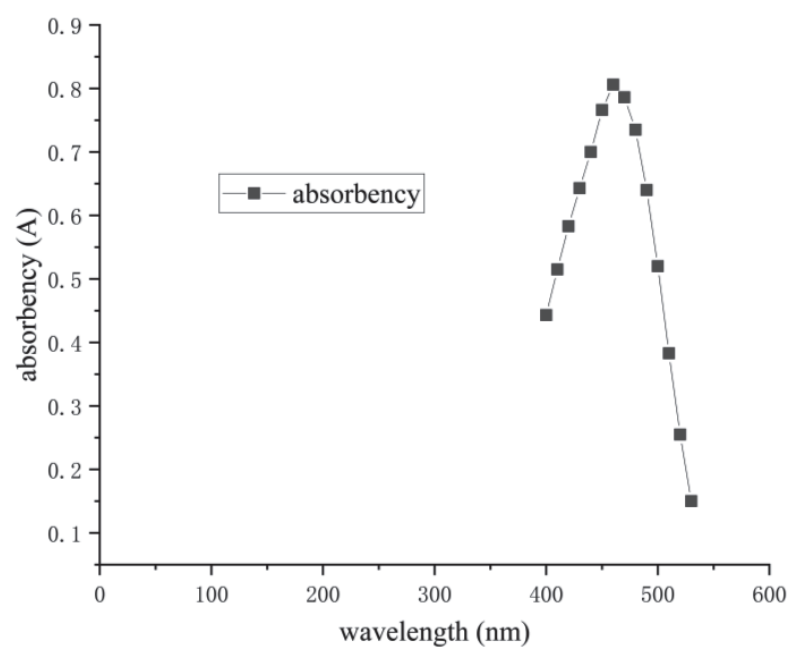

Fig. 2. The curve of absorbency-wavelength

from the figure that the methyl orange solution has the maximum peak at $460 \mathrm{~nm}$ wavelength, therefore was chosen $460 \mathrm{~nm}$ as the absorption wavelength of the methyl orange in this test.

The chromaticity is represented by the absorbance value at the maximum absorption wavelength, The water samples of different concentrations were removed for $10 \mathrm{~mL}$, first centrifuged and then diluted to a certain multiple with distilled water, then mixed evenly. The absorbance of water samples with different degradation degrees was determined with distilled water at $460 \mathrm{~nm}$ wavelength with a colorimetric dish of $10 \mathrm{~mm}$. The absorbance of water samples was determined with distilled water as reference. The standard curve is shown in Fig. 3.

In the experiment, the chroma removal rate is calculated according to the following formula:

$$
\eta=\frac{A_{0}-A_{t}}{A_{0}} \times 100 \%
$$

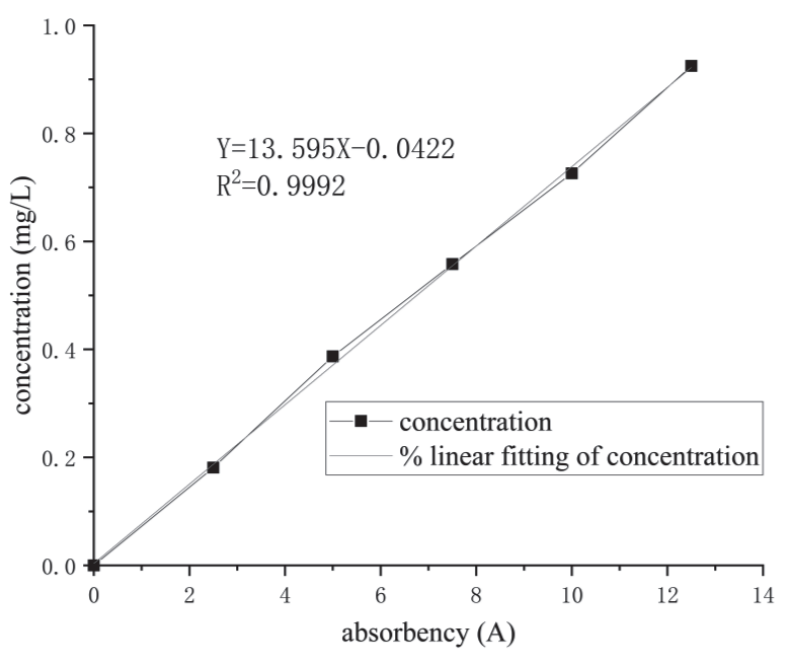

Fig. 3. The standard curve of concentration-absorbency. 
Where $\eta(\%)$ represents the removal rate of chroma, $\mathrm{A}_{0}(\mathrm{~A})$ and $\mathrm{A}_{\mathrm{t}}(\mathrm{A})$ represent the dye absorbance at time 0 and time $t$, respectively.

\section{Determination of $\mathrm{pH}$}

The $\mathrm{pH}$ was measured by Glass Electrode Method. Tests was conducted under neutral conditions.

\section{One-Factor Analysis}

For exploring the effect of different reaction factors on the degradation effect of methyl orange, the decolorization rate of dyes under different voltage, electrolyte dosage, distance between the plates, aeration and other test conditions were investigated, and the optimal conditions of the reaction were determined by comprehensive analysis.

\section{Response Surface Analysis}

If there is a significant interaction between factors, the optimal conditions obtained by one-factor analysis will be different from the results of the multivariate optimization. The larger the interaction effects the greater the difference will be found. Therefore, the results of one-factor tests may be biased because the influence of one factor may depend on the level of other factors involved in optimization. This is why the level of all factors should be designed to change at the same time, that is, the importance of response surface analysis. The first step of multivariate optimization is to screen the studied factors and obtain the best operating conditions through more complex experimental design after determining the important factors [13].

The response surface optimization design BoxBehnken Design (BDD) model is used in this study, and the three factors and three levels test design is carried out by Design-Expert software. According to the previous one-factor test, the range of factor level was determined, and 17 groups of tests were carried out. According to the statistical requirements of the Box-Behnken Design test design, the decolorization rate of methyl orange is in accordance with the quadratic polynomial model by comparing the variance analysis of different models such as linear, quadratic and cubic:

$$
\begin{aligned}
\mathrm{Y}=\mathrm{b}_{0} & +\sum_{i=1}^{\mathrm{k}} \mathrm{b}_{\mathrm{i}} \mathrm{X}_{\mathrm{i}}+\sum_{i=1}^{k} \mathrm{~b}_{\mathrm{ii}} \mathrm{X}_{\mathrm{i}}^{2} \\
& +\sum_{i=1}^{k-1} \sum_{j=i+1}^{k} \mathrm{~b}_{\mathrm{ij}} \mathrm{X}_{\mathrm{i}} \mathrm{X}_{\mathrm{j}}
\end{aligned}
$$

...where $\mathrm{Y}$ represents the response value, $\mathrm{b}_{0}$ represents the central point correction response, $b_{i}, b_{i i}$ and $\mathrm{b}_{\mathrm{ij}}$ represent the Linear, quadratic and interaction coefficient, respectively. $\mathrm{X}_{\mathrm{i}}, \mathrm{X}_{\mathrm{j}}$ was coded for different independent variables.

\section{Results and Discussion}

One-Factor Analysis

$$
\text { Effect of the Dose of the } \mathrm{Na}_{2} \mathrm{SO}_{4}
$$

In the electrochemical system, in order to improve the conductivity of refractory organic wastewater solution, it is necessary to add the proper amount of electrolyte to the reaction system, so as to increase the current density, remove the organic pollutants quickly, and make the electrolytic reaction proceed smoothly. Direct electrolytes should have good conductivity, stability, and be soluble in water. The commonly used electrolytes are $\mathrm{H}_{2} \mathrm{SO}_{4}$ for acids, $\mathrm{NaOH}, \mathrm{KOH}$ for alkali, $\mathrm{Na}_{2} \mathrm{SO}_{4}, \mathrm{NaCl}$ for salts and so on. The condition chosen in this experiment is neutral, so the electrolyte $\mathrm{Na}_{2} \mathrm{SO}_{4}$ or $\mathrm{NaCl}$ of salt can only be chosen, but $\mathrm{NaCl}$ is used as an electrolyte, it is easy to produce refractory halides in the process of wastewater treatment, so the electrolyte used in this experiment is $\mathrm{Na}_{2} \mathrm{SO}_{4}$.
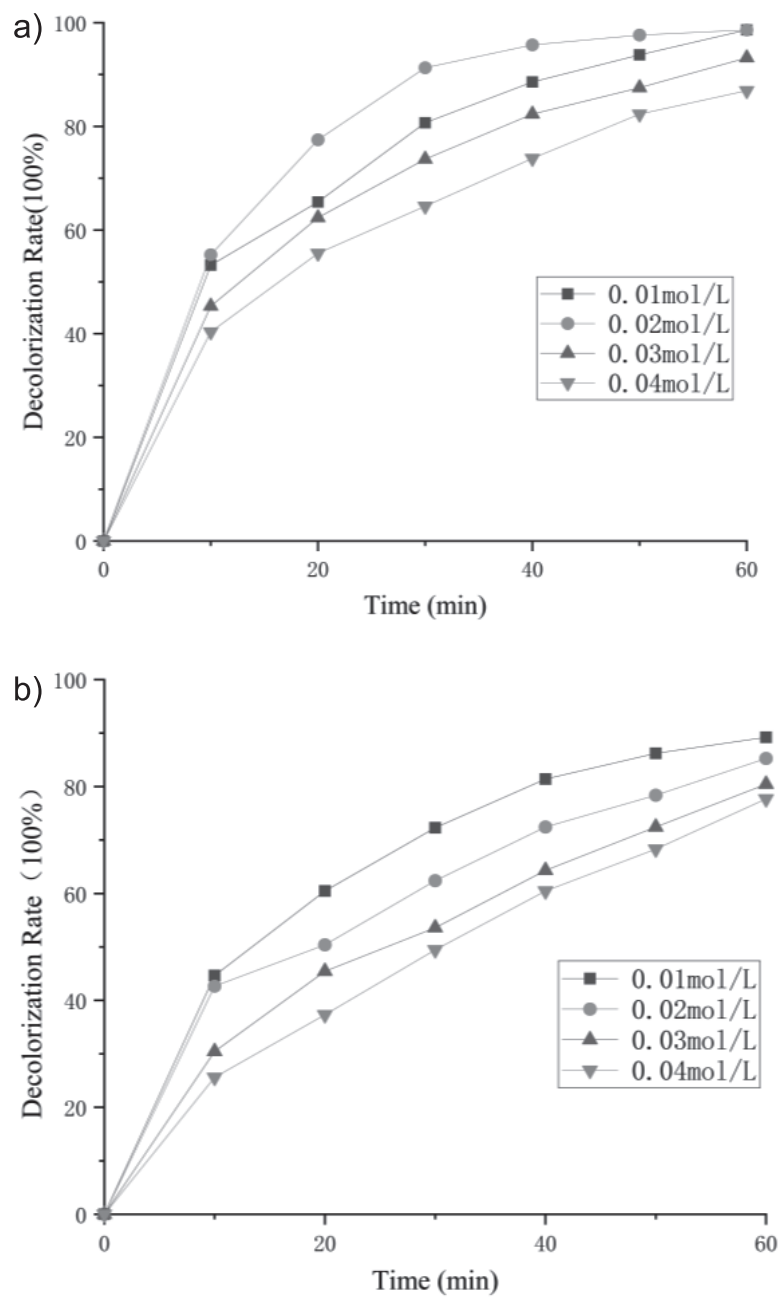

Fig. 4. Decolorization rate of methyl orange in the anode room(left) and cathode room(right) at (a) varying initial electrolyte dosage (initial concentration - $100 \mathrm{mg} / \mathrm{L}, \mathrm{pH}-7.0$, voltage $-20 \mathrm{~V}$, distance between electrodes $-4 \mathrm{~cm}$, aeration rate - $2.0 \mathrm{~L} / \mathrm{min}$ ). 
Fig. 4 shows the decolorization of methyl orange in the cathode chamber and the anode chamber under different electrolyte dosage. The results show that if the electrolyte concentration is too low, the conductivity of the solution is low, which is not conducive to the degradation reaction; however, if the electrolyte concentration is too high, the hydrogen evolution side reaction will accelerate, the power expenditure will increase, and a large number of bubbles will be generated, which decreases the mass transfer rate; thus, the decolorization effect will be changed [14]. Based on the results, the optimum amount of $\mathrm{Na}_{2} \mathrm{SO}_{4}$ is $0.02 \mathrm{~mol} / \mathrm{L}$.

\section{Effect of Voltage}

Voltage is a necessary condition for electrochemical reaction. It is the driving force for electrolysis, which determines the electrode potential of the cathode and anode plates, but the removal of organic matter is unfavorable when the applied voltage exceeds the reactor load. Therefore, it is very important to control the voltage and select the appropriate voltage to test it.

As seen from Fig. 5, there is an optimum value for the effect of voltage on the decolorization rate of methyl orange. When the voltage is $20 \mathrm{~V}$, the decolorization effect of methyl orange is the best, and the decolorization rates of methyl orange in the cathode and anode chambers are $90.23 \%$ and $98.60 \%$, respectively. When the voltage is increased from 5 to $20 \mathrm{~V}$, the decolorization rate is significantly improved. As the voltage increases, the electric field begins to increase, and the $\mathrm{H}_{2} \mathrm{O}_{2}$ produced by the reduction in the cathode chamber increases. The concentrations of $\bullet \mathrm{OH}$, $\cdot \mathrm{O}^{2-}$, and $\mathrm{HO}^{2-}$ also increase. Therefore, the degradation efficiency improves, while the amount of active oxygen generated in the anode chamber also increases, which promotes the progress of the reaction. When the voltage continues to increase, the decolorization rate decreases because when the voltage is too high, the electrolysis side reaction begins to increase; moreover, too high a voltage will cause a large amount of bubbles on the surface of the plate [15], affecting the degradation effect. Thus, $20 \mathrm{~V}$ is determined to be the optimal tank voltage.

\section{Effect of the Distance between Electrodes}

The electrode plate is the basis of electrochemical reaction. Not only the electrode plate material has an effect on the reaction effect, but also the distance between the plates has a direct effect on the reaction results. The distance between electrodes determines the size of the resistance in the electrolytic cell, the transfer distance of electrons and the transfer speed of matter, etc., thus affecting the energy consumption during the reaction. Choosing the appropriate distance between electrodes is not only beneficial to improve
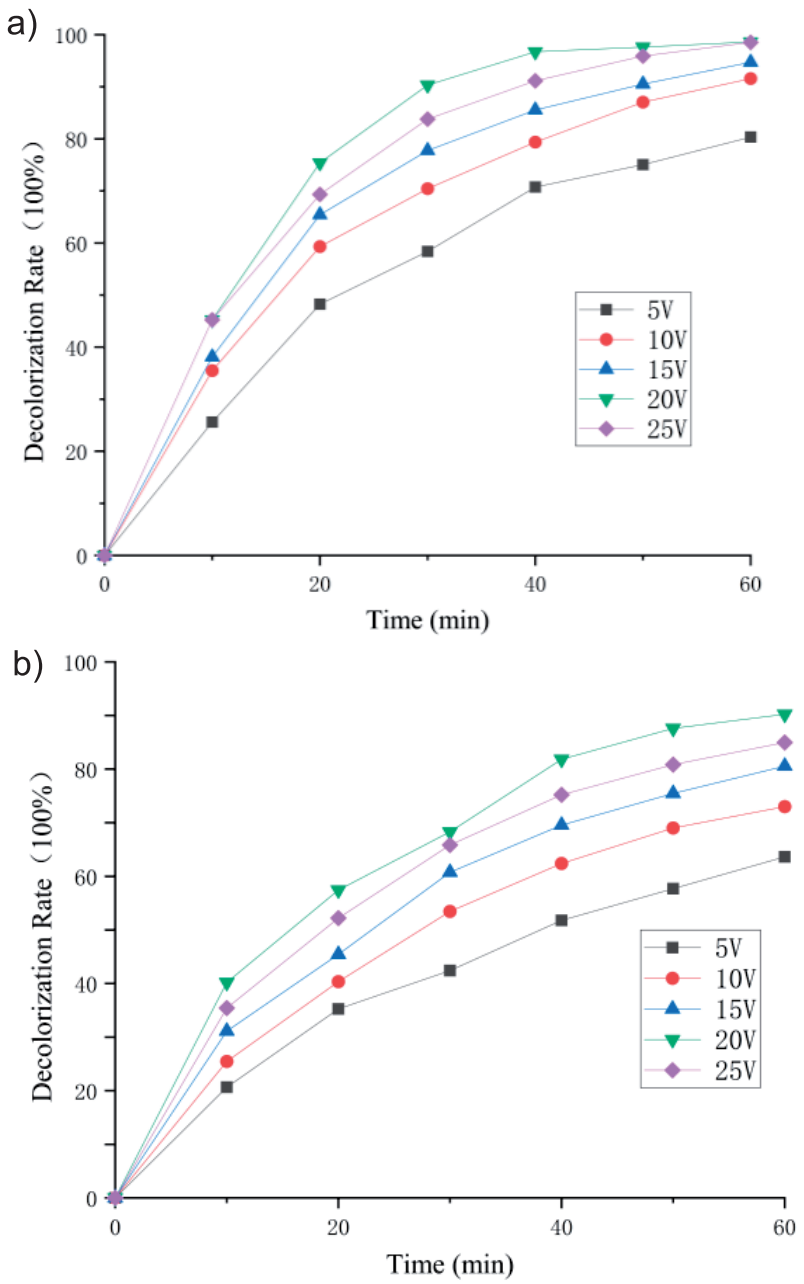

Fig. 5. Decolorization rate of methyl orange in the anode room(left) and cathode room(right) at (a) varying initial voltages (initial concentration - $100 \mathrm{mg} / \mathrm{L}, \mathrm{pH}-7.0$, distance between electrodes $-4 \mathrm{~cm}$, aeration rate $-2.0 \mathrm{~L} / \mathrm{min}$, electrolyte dose $-0.02 \mathrm{~mol} / \mathrm{L}$ ).

the reaction efficiency, but also can effectively reduce the energy consumption, thus improving the removal rate of organic matter.

Fig. 6 shows that as the distance between the plates increases, the decolorization rate of methyl orange in the cathode and anode chambers first increases and then decreases. When the distance between electrodes is increased from 1 to $4 \mathrm{~cm}$, the decolorization rate of methyl orange in the cathode chamber increases from 85.32 to $89.23 \%$, and the decolorization rate of methyl orange in the anode chamber increases from 95.38 to $98.60 \%$. When the distance between electrodes is small, the internal resistance of the reactor is also small, and the current is large, but at this time, the concentration polarization of the solution is very high, and the current efficiency is low, thereby affecting the decolorization effect of methyl orange. As the distance between electrodes increases, the resistance also increases. At this time, the mass transfer efficiency of the solution is high, and the decolorization effect 

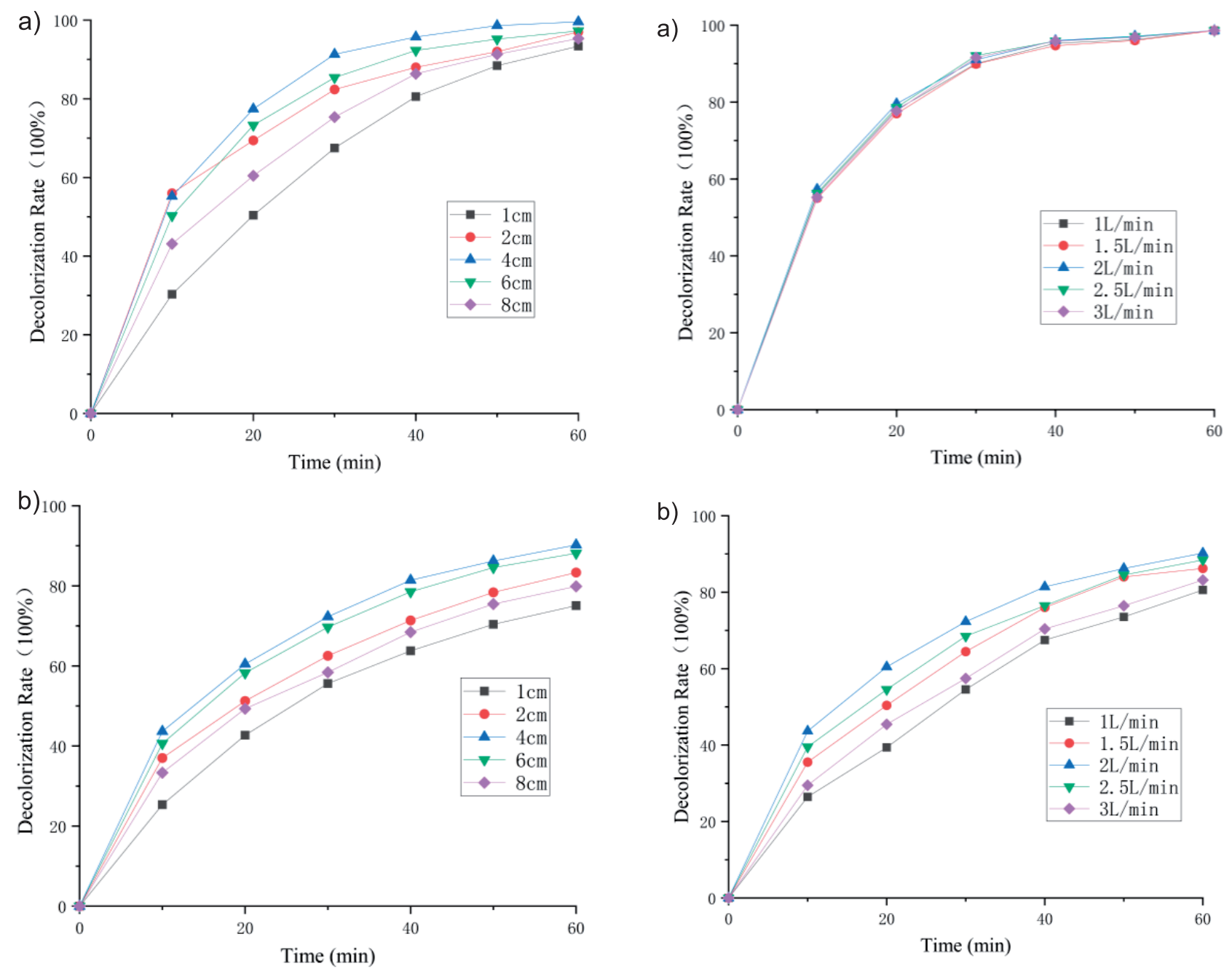

Fig. 6. Decolorization rate of methyl orange in the anode room(left) and cathode room(right) at a) varying initial distance between electrodes (initial concentration - $100 \mathrm{mg} / \mathrm{L}$, $\mathrm{pH}-7.0$, voltage $-20 \mathrm{~V}$, aeration rate $-2.0 \mathrm{~L} / \mathrm{min}$, electrolyte dose $-0.02 \mathrm{~mol} / \mathrm{L}$ ).

of methyl orange is remarkably improved. However, when the distance between electrodes exceeds $4 \mathrm{~cm}$, the decolorization rate of methyl orange in the anode and cathode chambers drops sharply. This result is because excessive electrical resistance decreases the electric field strength while the mass transfer distance increases, thereby affecting the degradation of organic matter [16]. Therefore, the optimal distance between electrodes is 4 $\mathrm{cm}$.

\section{Effect of the Aeration Rate}

In the electro-chemical oxidation unit of diaphragm system, there are three-phase interface reactions of gas, liquid and solid, so aeration is very important. In the process of electrolysis, the air provided by the air compressor enters the bottom aeration pipe of the reactor through the intake pipe and then enters the electrolytic cell through the air distribution plate.

Fig. 7. Decolorization rate of methyl orange in the anode room(left) and cathode room(right) at a) varying initial aeration rate (initial concentration - $100 \mathrm{mg} / \mathrm{L}, \mathrm{pH}-7.0$, voltage - $20 \mathrm{~V}$, distance between electrodes $-4 \mathrm{~cm}$, electrolyte dose $-0.02 \mathrm{~mol} / \mathrm{L})$.

On the one hand, the aeration can increase stirring, reduce the short-circuit current, increase the effective reaction current and increase electrode area for degradation of organic matter. On the other hand, the aeration can provide oxygen needed for the reaction, thus producing hydrogen peroxide, further producing free radicals with stronger oxidation ability and improving mass transfer efficiency. Therefore, it is necessary to study the effect of aeration flux on the treatment of simulated dye wastewater in the electrochemical oxidation of diaphragm system.

Fig. 7 shows that the effect of the aeration rate in the cathode chamber on the decolorization effect of methyl orange is the best when the aeration rate is $2.0 \mathrm{~L} / \mathrm{min}$, resulting in the decolorization rate of methyl orange being $89.23 \%$. When the aeration rate is low, the decolorization rate of methyl orange is also low. This is because the surface of the cathode is insufficiently supplied, so that the amount of $\mathrm{H}_{2} \mathrm{O}_{2}$ 
produced is also insufficient, and the amount of strong oxidizing radicals is also small, thereby resulting in the poor oxidative degradation of organic matter [17]. However, if the aeration rate is too high, the stirring effect is enhanced, the contact time between oxygen and the cathode surface is short, and the generated hydrogen peroxide and strong oxidizing radicals are easily destroyed [18], thereby reducing the decolorization rate of methyl orange. A high aeration rate in the anode chamber is better than a low aeration rate for the decolorization of methyl orange, but the effect is not obvious. Considering that aeration may play a role in heat transfer and heat dissipation, the optimal overall aeration rate is $2.0 \mathrm{~L} / \mathrm{min}$.

\section{Spectroscopic Analysis of the Reaction Mechanism of Electrochemical Oxidation}

Fig. 8a) shows that methyl orange has two main absorption peaks in the UV-Vis region, which are 263 and $470 \mathrm{~nm}$. According to the molecular structure of methyl orange and persistent organic pollutant (POP) theory, the peak at $263 \mathrm{~nm}$ is caused by the $\pi-\pi^{*}$ transition of the benzene ring conjugated system of methyl orange, and the peak at $470 \mathrm{~nm}$ is caused by the azo structure $n-\pi^{*}$ transition of methyl orange $[19,20]$.
The two peak values of the reaction gradually weaken until the reaction disappears for $60 \mathrm{~min}$, indicating that both the $\pi-\pi^{*}$ bond and the azo structure $n-\pi^{*}$ bond of the benzene ring conjugated system of methyl orange is destroyed. The molecular structure changes, and the chromophore group no longer exists, thereby achieving discoloration.

As seen from Fig. 8b), before the start of electrolysis, there are two absorption peaks in the water sample, which are again at 263 and $470 \mathrm{~nm}$. During the electrolysis process, the absorption peak at $470 \mathrm{~nm}$ redshifts to $508 \mathrm{~nm}$ because the anode chamber quickly becomes acidic $(\mathrm{pH}<3)$ after the start of electrolysis, and methyl orange is red under acidic conditions. The colour of azo dye is primarily determined by the azo bond and its associated chromophore and cocolour groups. After $30 \mathrm{~min}$, the absorption peak disappears at $508 \mathrm{~nm}$, but there is still an absorption peak in the region below $470 \mathrm{~nm}$, indicating that there is still an intermediate product in the solution. It can also be seen that there is no new absorption peak in the process of degrading methyl orange in the anode chamber, indicating that the degradation of methyl orange is caused by the destruction of its chromophore group.

a)

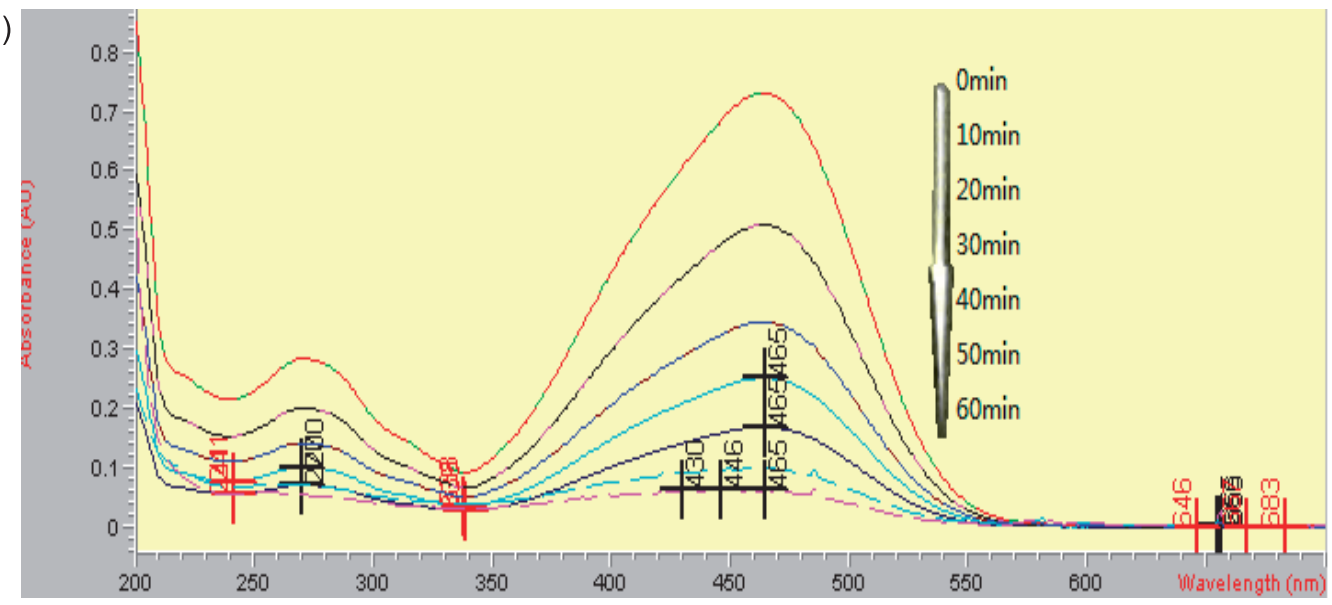

b)

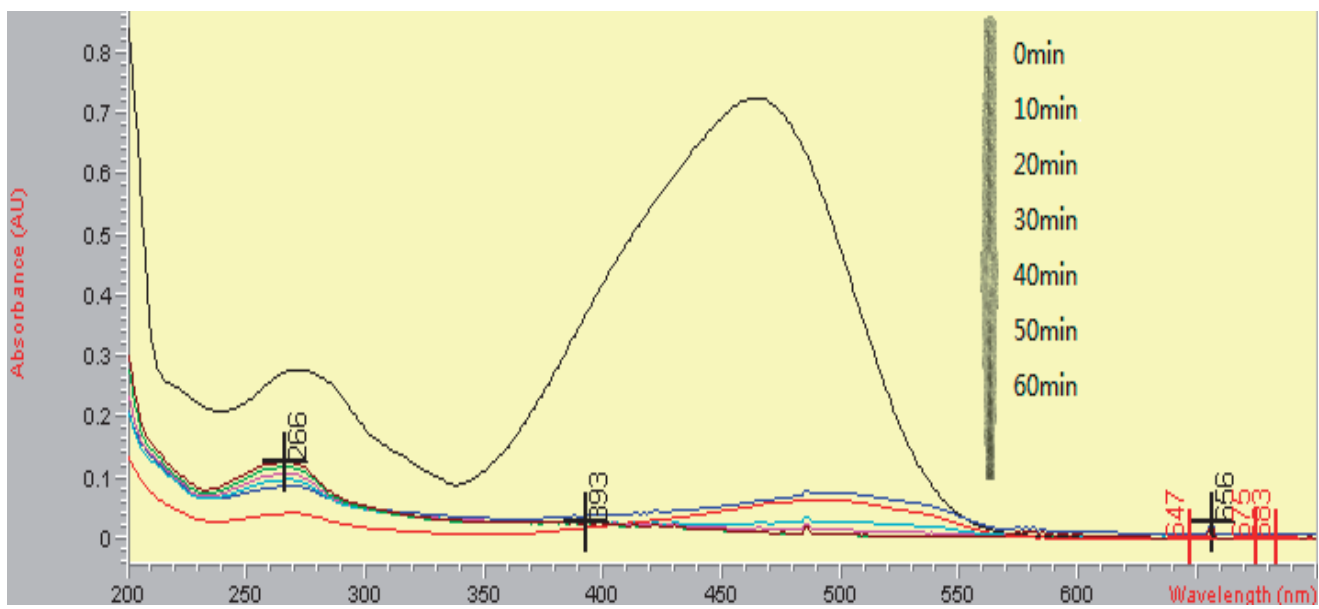

Fig. 8. UV-vis Spectrum during the reaction in the cathode room a) and anode room b). 


\section{Diaphragm System Energy Analysis}

According to Fig. 9, regression analysis was carried out on the relationship between the voltage in the cathode chamber and anode chamber and the decolorization rate [21, 22]. The cathode chamber regression equation can be expressed as:

$$
\mathrm{E}_{1}=2.2515 \mathrm{U}_{1}+50.403 \quad \mathrm{R}^{2}=0.9999
$$

After conversion:

$$
\begin{gathered}
U_{1}=0.4441 E_{1}-22.384 \\
\mathrm{I}_{1}=0.024 \mathrm{E}_{1}-1.19
\end{gathered}
$$

The relationship between the energy expenditure and decolorization rate in the cathode chamber can be expressed as:

$$
W_{1}=\left(0.011 E_{1}^{2}-1.07 E_{1}+26.64\right) t
$$

...where $\mathrm{E}_{1}(\%)$ represents the decolorization rate of methyl orange in the cathode chamber, $\mathrm{U}_{1}(\mathrm{~V}) \mathrm{I}_{1}(\mathrm{~A})$ and $\mathrm{W}_{1}(\mathrm{~J})$ represent Voltage , Current and Electricity, respectively.

The anode chamber regression equation can be expressed as:

$$
E_{2}=2.5875 U_{2}+65.929 R^{2}=0.9953
$$

After conversion:

$$
U_{2}=0.3841 E_{2}-25.284
$$

$$
\mathrm{I}_{2}=0.02 \mathrm{E}_{2}-1.33
$$

The relationship between the energy expenditure and decolorization rate in the anode chamber can be expressed as:

$$
W_{2}=\left(0.008 E_{2}^{2}-1.01 E_{2}+33.63\right) t
$$

...where $\mathrm{E}_{2}(\%)$ represents the decolorization rate of methyl orange in the anode chamber, $\mathrm{U}_{2}(\mathrm{~V}) \mathrm{I}_{2}(\mathrm{~A})$ and $\mathrm{W}_{2}(\mathrm{~J})$ represent Voltage, Current and Electricity, respectively.

\section{Response Surface Design and Results}

It can be seen from the results of one-factor analysis that the effect of the distance between electrodes, voltage and aeration on the decolorization rate of methyl orange is greater than that of electrolyte dosage, Therefore, The three factors affecting the decolorization rate of methyl orange, namely, distance between electrodes, voltage and aeration rate, are chosen as variables $\mathrm{X} 1, \mathrm{X} 2$, and $\mathrm{X} 3$, respectively. The response value is the decoloration rate of the anode chamber (Y1) and cathode chamber (Y2). The Box-Behnken design model in Design-Expert 10.0.4 software is designed as a 3-factor 3-level experiment. The statistical significance of the model equations and parameters is evaluated by analysis of variance (ANOVA) and the P value (significance level). ANOVA is used to identify and estimate linear effects, quadratic effects, and interactions. The quality of the model is determined by the R2 value of the adjusted model. The range of factors are determined according to the previous one-factor test.

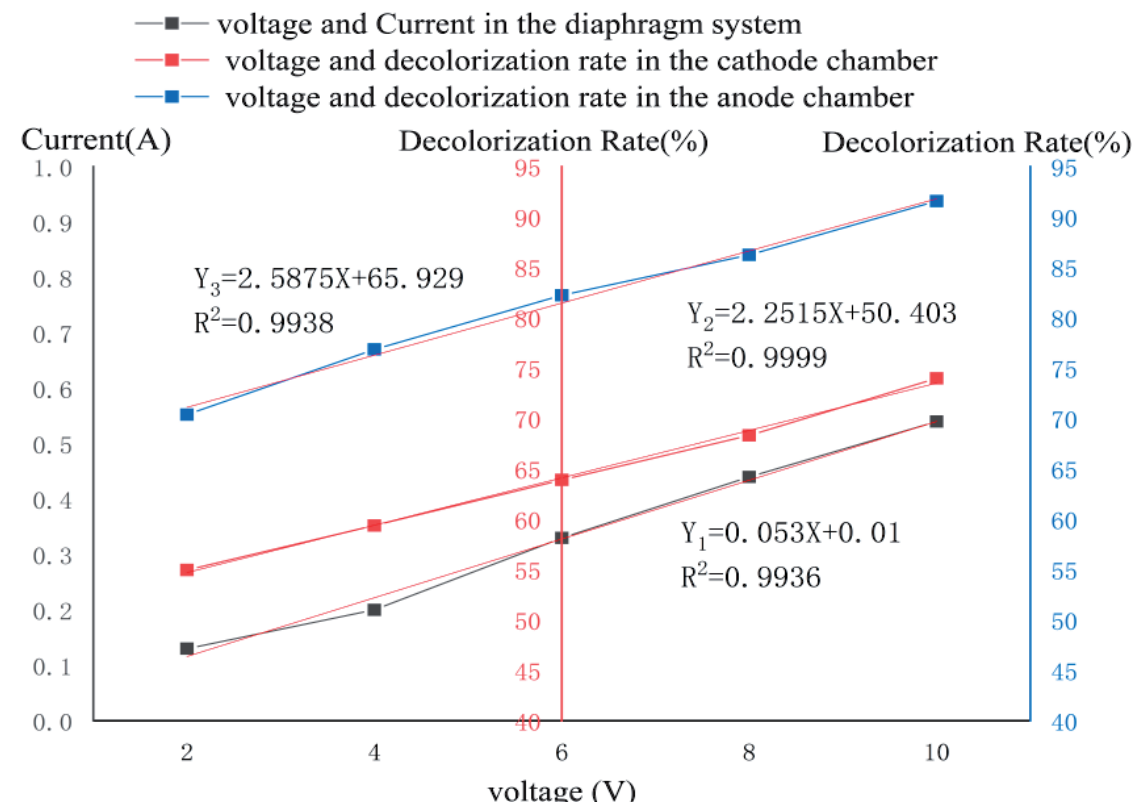

Fig. 9. The relationship between voltage and current in the diaphragm system (1); the relationship between the voltage an decolorization rate in the cathode chamber (2); the relationship between the voltage and decolorization rate in the anode chamber (3). 
Table 1. Design Factor Coding and Level Experimental design.

\begin{tabular}{|c|c|c|c|c|}
\hline \multirow{2}{*}{ Factors } & \multirow{3}{*}{ Variable } & \multicolumn{3}{|c|}{ Level } \\
\cline { 3 - 5 } & & -1 & 0 & 1 \\
\hline Distance between electrodes $(\mathrm{cm})$ & $\mathrm{X}_{1}$ & 2 & 4 & 6 \\
\hline Voltage (V) & $\mathrm{X}_{2}$ & 15 & 20 & 25 \\
\hline Aeration rate (L/min) & $\mathrm{X}_{3}$ & 1.5 & 2 & 2.5 \\
\hline
\end{tabular}

Table 2. Experimental Design and Results of Response Surface.

\begin{tabular}{|c|c|c|c|c|c|}
\hline Number & $\begin{array}{c}\text { Distance between electrodes } \\
(\mathrm{cm})\end{array}$ & $\begin{array}{c}\text { Voltage } \\
(\mathrm{V})\end{array}$ & $\begin{array}{c}\text { Aeration rate } \\
(\mathrm{L} / \mathrm{min})\end{array}$ & $\begin{array}{c}\text { Decolorization rate of } \\
\text { anode chamber }(\%)\end{array}$ & $\begin{array}{c}\text { Decolorization rate of } \\
\text { cathode chamber }(\%)\end{array}$ \\
\hline 1 & 6 & 25 & 94.63 & 78.74 \\
\hline 2 & 6 & 20 & 2.5 & 96.84 & 84.33 \\
\hline 3 & 4 & 25 & 1.5 & 96.15 & 82.55 \\
\hline 4 & 4 & 20 & 2 & 98.58 & 89.23 \\
\hline 5 & 4 & 15 & 2.5 & 94.56 & 80.28 \\
\hline 6 & 4 & 20 & 2 & 98.57 & 88.85 \\
\hline 7 & 2 & 25 & 2 & 93.25 & 77.36 \\
\hline 8 & 2 & 15 & 2 & 92.76 & 73.22 \\
\hline 9 & 2 & 20 & 1.5 & 95.13 & 81.92 \\
\hline 10 & 4 & 25 & 2.5 & 97.26 & 89.18 \\
\hline 11 & 4 & 20 & 2 & 98.58 & 82.83 \\
\hline 12 & 2 & 20 & 2.5 & 95.55 & 85.14 \\
\hline 13 & 6 & 20 & 1.5 & 95.87 & 89.22 \\
\hline 14 & 4 & 20 & 2 & 98.54 & 76.25 \\
\hline 15 & 4 & 20 & 15 & 94.34 & 88.79 \\
\hline 16 & 4 & & 98.61 & 73.16 \\
\hline 17 & 4 & 2 & 93.37 & \\
\hline
\end{tabular}

Design factor codes and levels are shown in Table 1. The experimental design and results of the response surface are shown in Table 2.

Using the Design-Expert software, the ANOVA results of the regression model and decolorization rate are shown in Tables 3 and 4, respectively. The multivariate quadratic regression equation between factors and response values is obtained by data analysis as follows:

$$
\begin{gathered}
\mathrm{Y}_{1}=98.58+0.50 \mathrm{X}_{1}+0.78 \mathrm{X}_{2}+0.34 \mathrm{X}_{3} \\
+0.19 \mathrm{X}_{1} \mathrm{X}_{2}+0.14 \mathrm{X}_{1} \mathrm{X}_{3}+0.22 \mathrm{X}_{2} \mathrm{X}_{3} \\
-2.40 \mathrm{X}_{1}^{2}-2.67 \mathrm{X}_{2}^{2}-0.33 \mathrm{X}_{3}^{2} \\
\mathrm{Y}_{2}=89.05+1.17 \mathrm{X}_{1}+2.21 \mathrm{X}_{2}+0.86 \mathrm{X}_{3} \\
+0.36 \mathrm{X}_{1} \mathrm{X}_{2}-1.27 \mathrm{X}_{1} \mathrm{X}_{3}-1.16 \mathrm{X}_{2} \mathrm{X}_{3}-5.48 \mathrm{X}_{1}^{2} \\
-7.95 \mathrm{X}_{2}^{2}-0.85 \mathrm{X}_{3}^{2}
\end{gathered}
$$

Table 3a) shows that the correlation coefficient of the model (R-Squared) is 0.9860 , which indicates that the correlation between the experimental data and the proposed model is acceptable, the Radj2R1 is 0.9680 , and the Rpred2R1 is 0.7762; that is, the difference between the correction coefficient and the prediction coefficient is small, which indicates that the predicted value of the model fits well with the experimental data. Table 3 (2) is similar to that mentioned above.

According to Table 4, the $\mathrm{F}$ values of the model are 54.69 and 61.00 , respectively. Clearly, the model is significant, which means that the studied parameters

Table 3a). ANOVA results of regression models R1.

\begin{tabular}{|c|c|c|c|}
\hline Std. Dev. & 0.37 & R-Squared & 0.9860 \\
\hline Mean & 96.03 & Adj R-Squared & 0.9680 \\
\hline C.V. $\%$ & 0.38 & Pred R-Squared & 0.7762 \\
\hline PRESS & 15.25 & Adeq Precision & 21.762 \\
\hline
\end{tabular}


Table 3b). ANOVA results of regression models R2

\begin{tabular}{|c|c|c|c|}
\hline Std. Dev. & 0.95 & R-Squared & 0.9874 \\
\hline Mean & 82.33 & Adj R-Squared & 0.9712 \\
\hline C.V. $\%$ & 1.15 & Pred R-Squared & 0.8039 \\
\hline PRESS & 97.76 & Adeq Precision & 22.656 \\
\hline
\end{tabular}

have a significant impact on the response. On the other hand, the order of the three factors in the two tables affecting the removal effect of methyl orange can be obtained from the $F$ value: voltage $>$ distance between electrodes $>$ aeration rate; furthermore, the $\mathrm{P}$ value of the model is less than 0.0001 . This result shows that the model is reliable for predicting the decolorization rate of methyl orange.

\section{Two-Factor Interaction Effect Analysis}

The contours and response surfaces of the interaction between the three factors affecting the decolorization rate of methyl orange are shown in Figs 10 to 13, respectively. The response surface diagram is used to obtain the best value for each factor and to evaluate the interaction of independent variables, while other factors are fixed at their best value.

In the contour map, if the centre position is elliptical, the interaction between the two factors is significant; a circle at centre position indicates that the interaction

Table 4a). ANOVA results of the decolourization rate of methyl orange in the anode chamber.

\begin{tabular}{|c|c|c|c|c|c|}
\hline Project & Total variances & Degree of freedom & $F$ & $P$ & - \\
\hline Model & 67.18 & 9 & 54.69 & $<0.0001$ & Significant \\
\hline $\mathrm{X}_{1}$ & 2.02 & 1 & 14.80 & 0.0063 & \\
\hline $\mathrm{X}_{2}$ & 4.90 & 1 & 35.89 & 0.0005 & \\
\hline $\mathrm{X}_{3}$ & 0.92 & 1 & 6.78 & 0.0353 & \\
\hline $\mathrm{X}_{1} \mathrm{X}_{2}$ & 0.15 & 1 & 1.09 & 0.3320 & \\
\hline $\mathrm{X}_{1} \mathrm{X}_{3}$ & 0.076 & 1 & 0.55 & 0.4809 & \\
\hline $\mathrm{X}_{2} \mathrm{X}_{3}$ & 0.20 & 1 & 1.45 & 0.2675 & \\
\hline $\mathrm{X}_{1}^{2}$ & 24.29 & 1 & 220.22 & $<0.0001$ & \\
\hline $\mathrm{X}_{2}^{2}$ & 30.06 & 1 & 3.29 & 0.1124 & \\
\hline $\mathrm{X}_{3}^{2}$ & 0.45 & 7 & 504.15 & $<0.0001$ & Significant \\
\hline Residual & 0.96 & 3 & 54.69 & $<0.0001$ & \\
\hline Lack of Fit & 0.95 & & & & \\
\hline
\end{tabular}

Table 4(2). ANOVA results of the decolorization rate of methyl orange in the cathode chamber.

\begin{tabular}{|c|c|c|c|c|c|}
\hline Project & Total variances & Degree of freedom & $\mathrm{F}$ & $\mathrm{P}$ & - \\
\hline Model & 492.31 & 9 & 61.00 & $<0.0001$ & Significant \\
\hline$X_{1}$ & 11.02 & 1 & 12.29 & 0.0099 & \\
\hline $\mathrm{X}_{2}$ & 38.98 & 1 & 43.47 & 0.0003 & \\
\hline $\mathrm{X}_{3}$ & 5.87 & 1 & 6.54 & 0.0377 & \\
\hline $\mathrm{X}_{1} \mathrm{X}_{2}$ & 0.52 & 1 & 0.58 & 0.4719 & \\
\hline$X_{1} X_{3}$ & 6.43 & 1 & 7.17 & 0.0317 & \\
\hline $\mathrm{X}_{2} \mathrm{X}_{3}$ & 5.43 & 1 & 6.05 & 0.0434 & \\
\hline $\mathrm{X}_{1}^{2}$ & 126.59 & 1 & 141.17 & $<0.0001$ & \\
\hline $\mathrm{X}_{2}^{2}$ & 266.17 & 1 & 296.80 & $<0.0001$ & \\
\hline $\mathrm{X}_{3}^{2}$ & 3.07 & 1 & 3.42 & 0.1069 & \\
\hline Residual & 6.28 & 7 & & & \\
\hline Lack of Fit & 6.09 & 3 & 43.73 & 0.0016 & Significant \\
\hline
\end{tabular}


a)

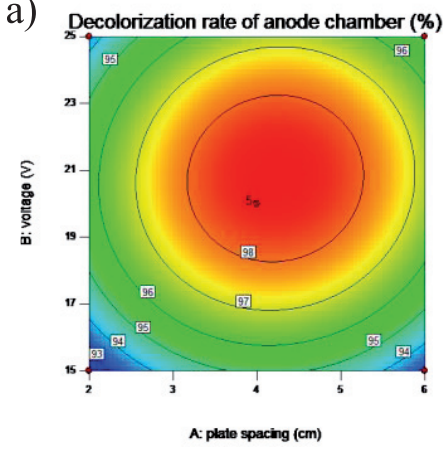

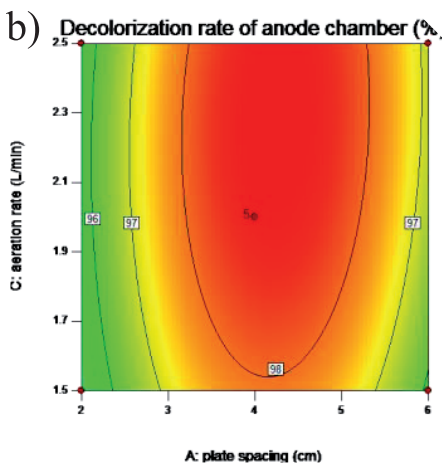

Fig. 10. Contour graphs of the distance between electrodes/Voltage a), distance between electrodes/Aeration rate b), Voltage/Aeration rate c).

a)

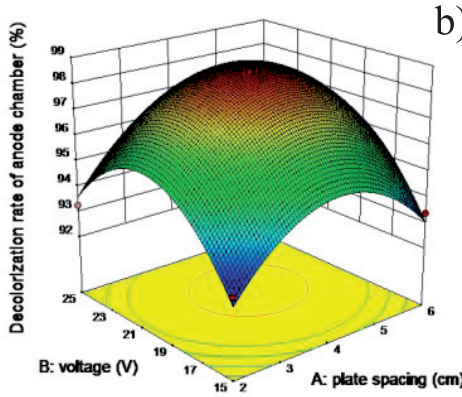

b)

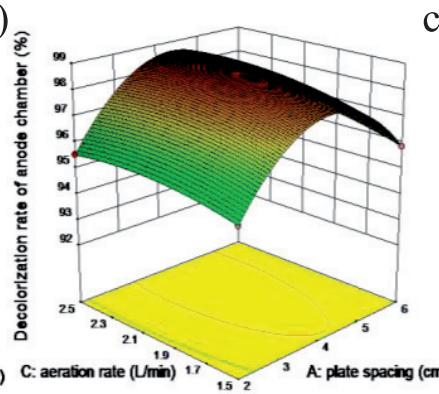

c) Decolorization rate of anode chamber $(\%$,

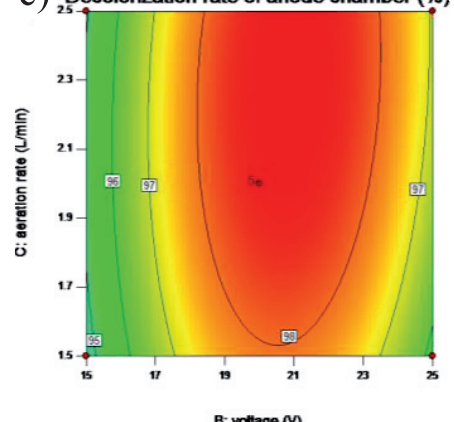

Fig. 11. Surface plots of the distance between electrodes/Voltage a), distance between electrodes/Aeration rate b), Voltage/Aeration rate c).

a)

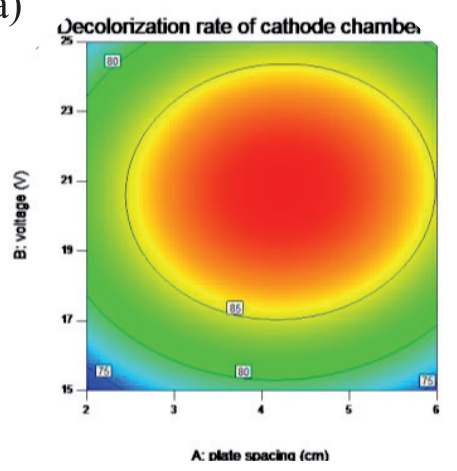

b)

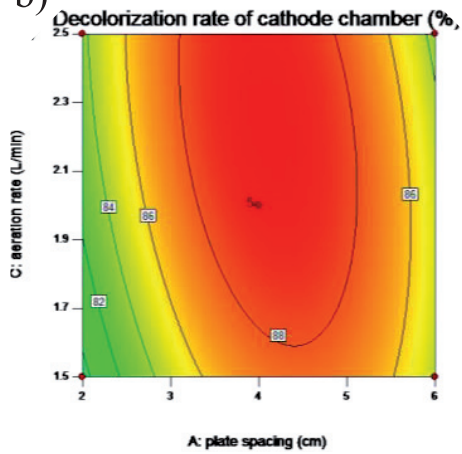

c)

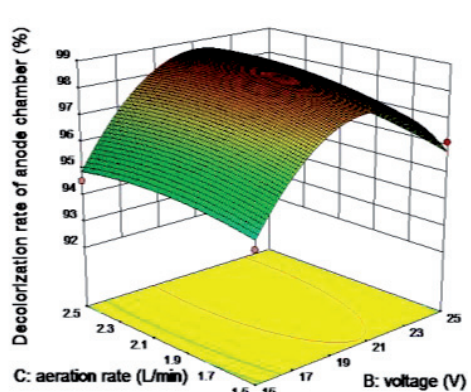

Fig. 12. Contour graphs of the distance between electrodes/Voltage a), distance between electrodes/Aeration rate b), Voltage/Aeration rate c).

a)

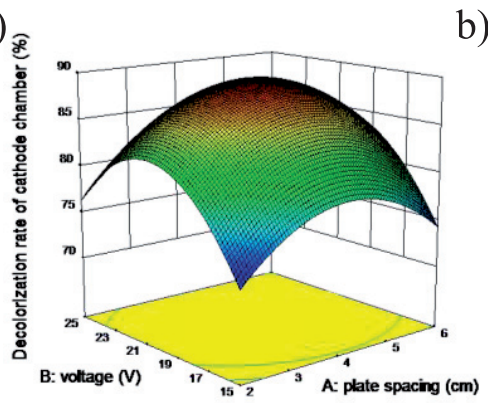

b)

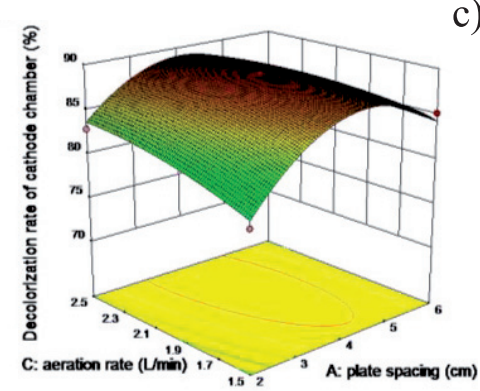

c)

C) Decolorization rate of cathode chamber (\%)

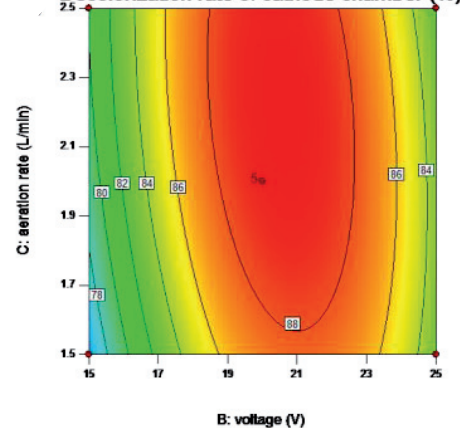

voltage (V) 
between the two factors is weaker, and in the response surface diagram, the steep slope of the response surface indicates that the response value changes more sensitively.

Figs 10-11 show the interaction between the three factors in the anode chamber. From the contour map, can be seen that Fig. 10a) is micro-circular; that is, the interaction between the two factors is not significant. Fig. 10(b-c) are ovals, so the interaction is significant. It can be seen from the diagram that with increasing voltage, decolorization first increases and then decreases, while the change in the distance between the plates and aeration amount is the same as that of voltage. The optimum values are approximately 4 for the distance between electrodes, 2.0 for aeration rate and 20 for voltage. This result is consistent with the one-factor test. The response surface diagram shows that the methyl orange removal rate is sensitive to changes in the voltage and aeration rate, but the effect of voltage is greater than that of distance between electrodes. By analyzing the reasons, the increase in voltage will intensify the side reaction, and at the same time, it will produce a large number of bubbles on the surface of the plate. Additionally, excessive aeration will aggravate this effect; thus, hydrogen peroxide and strong oxidizing free radicals are more easily destroyed.

Figs 12-13 reflect the interaction among the three factors in the cathode chamber. The optimum values are also approximately 4 for the distance between electrodes, 2.0 for aeration rate and 20 for voltage. The response laws of the cathode and anode chambers are similar, and the response effect is remarkable.

\section{Conclusions}

In the electrochemical reaction of the anode and cathode in a diaphragm system, some factors have a large influence on the decolorization effect of dye wastewater. After optimization by response surface methodology, the optimal process conditions for the treatment of methyl orange solution with a mass concentration of $100 \mathrm{mg} / \mathrm{L}$ in the separated system were as follows: the dose of $\mathrm{Na}_{2} \mathrm{SO}_{4}$ electrolyte was $0.02 \mathrm{~mol} / \mathrm{L}$, the voltage was $20.56 \mathrm{~V}$, and the distance between electrodes was $4.4 \mathrm{~cm}$. Additionally, the gas velocity was $2.21 \mathrm{~L} / \mathrm{min}$. Under optimal conditions, the decolorization rate reached $90.81 \%$ in the cathode chamber and $98.75 \%$ in the anode chamber. The most important factor affecting the decolorization rate was the cell voltage, and the two factors with the most interaction were the cell voltage and the distance between electrodes. The relationship between the energy expenditure and decolorization rate in the cathode is: $W_{1}=\left(0.0369 E_{1}^{2}-5.344 E_{1}+193.63\right) t$, while the relationship between the energy expenditure of the anode and the decolorization rate is: $W_{1}=\left(0.039 E_{2}{ }^{2}\right.$
- 6.667E +282.81$) t$. UV-Vis absorption spectroscopy indicated that there was both molecular structure destruction and mineralization during electrolysis. The anode chamber had a better decolorization effect, but the cathode chamber had a better degree of mineralization.

\section{Acknowledgements}

This work was financially supported by Liaoning Natural Science Fund Project (Z2415053).

\section{Conflict of Interest}

The authors declare no conflict of interest.

\section{References}

1. LAZHAR L., ANTONIO B., GIACOMO C., ABDELLATIF G., SALAH A., MARCO P. Role of anode material on the electrochemical oxidation of methyl orange. Journal of Solid State Electrochemistry, 19 (10), 3177, 2015.

2. TANTIS I., ANTONOPOULOU M., KONSTANINOU I., LIANOS P. Coupling of electrochemical and photocatalytic technologies for accelerating degradation of organic pollutants. Journal of Photochemistry \& Photobiology A Chemistry, 317, 100, 2016.

3. BU J., YUAN L., ZHANG N., LIU D., MENG Y., PENG $X$. High-efficiency adsorption of methylene blue dye from wastewater by a thiosemicarbazide functionalized graphene oxide composite. Diamond and Related Materials, 101, 107604, 2020.

4. WANG J., ZHANG T., MEI Y., PAN B. Treatment of reverse-osmosis concentrate of printing and dyeing wastewater by electro-oxidation process with controlled oxidation-reduction potential (ORP). Chemosphere, 201, 621, 2018.

5. SINGH R.L., SINGH P.K., SINGH R.P. Enzymatic decolorization and degradation of azo dyes - A review. International Biodeterioration \& Biodegradation, 104, 21, 2015.

6. MAHMOODI N.M., SALCHI R., ARAMI M. Binary system dye removal from Colored textile wastewater using activated carbon: Kinetic and isotherm studies. Desalination, 272 (1/2/3), 187, 2011.

7. AMA O.M., KUMAR N., ADAMS F.V., RAY S.S. Efficient and cost-effective photo electrochemical degradation of dyes in wastewater over an exfoliated graphite-moo3 nanocomposite electrode. Electrocatalysis, 2018.

8. DEGAKI A.H., PEREIRA G.F., ROCHA-FILHO R.C., BOCCHI N., BIAGGIO S.R. Effect of specific active chlorine species and temperature on the electrochemical degradation of the reactive blue 19 dye using a boron-doped diamond or dsa anode in a flow reactor. Electrocatalysis, 5(1), 8, 2014.

9. WEI J., LIU J., YAN W., ZHANG, X., ZHANG Y. Effectiveness of electrocatalysis oxidation treatment of herbicides clomazone wastwater. Chinese Journal of Environmental Engineering, 8 (2), 587, 2014, 
10. HU C., HU B., WANG Y., ZHANG Q., ZHOU X. Tio2 nanotube arrays based dsa electrode and application in treating dye wastewater. Russian Journal of Electrochemistry, 52 (5), 420, 2016.

11. CHENG X., PAN G., YU X. Visible light responsive photoassisted electrocatalytic system based on cds ncs decorated tio2 nano-tube photoanode and activated carbon containing cathode for wastewater treatment. Electrochimica Acta, 156, 94, 2015.

12. GOTTI G., FAJERWERG K., EVRARD D., GROS P. Electrodeposited gold nanoparticles on glassy carbon: correlation between nanoparticles characteristics and oxygen reduction kinetics in neutral media. Electrochimica Acta, 128, 412, 2014.

13. FERREIRA S.L.C., BRUNS R.E., FERREIRA H.S., MATOS G.D., DAVID J.M., BRANDÃO G.C., DA SILVA E.G.P., PORTUGAL L.A., DOS REIS P.S., SOUZA A.S., DOS SANTOS W.N.L. Box-Behnken design: an alternative for the optimization of analytical methods. Analytica chimica acta, 597 (2), 179, 2007.

14. JUANG Y., LIU Y., NURHAYATI E., THUY N., HUANG C., HU C.C. Anodic fabrication of advanced titania nanotubes photocatalysts for photo electrocatalysis decolorization of orange $g$ dye. Chemosphere, 144, 2462, 2016.

15. DAI Q., ZHOU J., MENG X., FENG D., WU C., CHEN J. Electrochemical oxidation of cinnamic acid with mo modified pbo2 electrode: electrode characterization, kinetics and degradation pathway. Chemical Engineering Journal, S1385894715017258, 2015.

16. PALMA-GOYES R.E., SILVA-AGREDO J., GONZÁLEZ IGNACIO, TORRES-PALMA R.A. Comparative degradation of indigo ca rmine by electrochemical oxidation and advanced oxidation processes. Electrochimica Acta, 140, 427, 2014.

17. COTILLAS S., LLANOS J., PABLO CAÑIZARES, CLEMATIS D., PANIZZA M. Removal of procion red $\mathrm{mx}-5 \mathrm{~b}$ dye from wastewater by conductive-diamond electrochemical oxidation. Electrochimica Acta, 263, 1, 2018.

18. ELOY ISARAIN-CH'AVEZ, MARIA DOLORS BAR'O, EMMA ROSSINYOL, ULISES MORALES-ORTIZ, JORDI SORT, ENRIC BRILLAS, EVA PELLICER Comparative electrochemical oxidation of methyl orange azo dye using ti/ir-pb, ti/ir-sn, ti/ru-pb, ti/pt-pd and ti/ruo 2, anodes. Electrochimica Acta, S0013468617310976, 2017.

19. ZOU J., PENG X., LI M., XIONG Y., WANG B., DONG F., WANG B. Electrochemical oxidation of cod from real textile wastewaters: kinetic study and energy consumption. Chemosphere, 171, 332, 2017.

20. XU L., ZHANG L., DU L., ZHANG S. Electrocatalytic oxidation in treating c.i. acid red 73 wastewater coupled with nanofiltration and energy consumption analysis. Journal of membrane science, 452, 1, 2014.

21. WANG J., BAI, R. Formic acid enhanced effective degradation of methyl orange dye in aqueous solutions under uv-vis irradiation. Water Research, 101, 103, 2016.

22. LIU J., LIU X., LI J., PAN L., ZHUO S. Enhanced visible light photocatalytic degradation of methyl orange by bi2o3/f-tio2 composites. Rsc Advances, 4 (73), 38594, 2014. 
